\title{
Intransitive competition and its effects on community functional diversity
}

\author{
Laure Gallien \\ L. Gallien (http://orcid.org/0000-0003-4882-1580)(laure.gallien@gmail.com), Centre for Invasion Biology, Dept of Botany and Zoology, \\ Stellenbosch Univ., ZA-7602 Matieland, South Africa.
}

\begin{abstract}
Can competitive interactions be inferred from the analysis of community functional diversity patterns? Originally, at the scale of a community, competitive interactions were supposed to generate trait overdispersion patterns due to limiting similarity process. More recently, by highlighting the importance of competitive hierarchies, it has been shown that when only one resource limits species coexistence, competition can also lead to patterns of trait clustering. However, these two expectations (overdispersion and clustering) ignore potential multi-species indirect competitive interactions, and especially intransitive competition. Indeed, little is yet known about intransitive competition and its influence on community's functional diversity.

Here I propose a brief appraisal of empirical evidence for intransitive competition in nature, and an overview of the current understanding of this mechanism and its properties. I then demonstrate with a theoretical model that intransitive competitive interactions can actually generate random-like functional diversity patterns.

The variety of diversity patterns (overdispersion, clustering, randomness) that can emerge from diverse types of competitive interactions makes it difficult to identify the presence of competition in nature, potentially leading to an underestimation of its importance as a structuring force. New methodologies able to capture both simple and complex competition mechanisms are thus urgently needed.
\end{abstract}

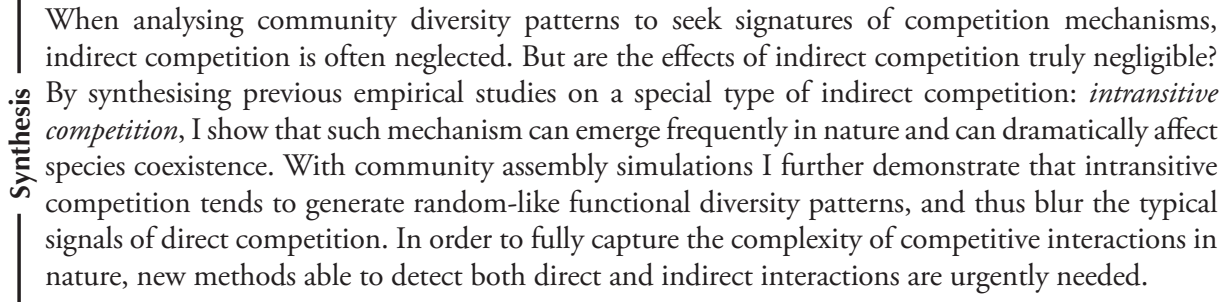

\section{Trait clustering and overdispersion, two established expectations}

One central aim of community ecology is to unravel the different mechanisms promoting and hampering species coexistence in the community. To this end, a large amount of empirical and theoretical work has been directed toward the analysis of community functional trait patterns, with a special focus on two mechanisms: environmental filtering and competitive interactions (Weiher and Keddy 1999, Götzenberger et al. 2012).

In this context, environmental filtering mechanism leads to clear expectations in terms of functional patterns: stressful environmental conditions should lead to the coexistence of species with similar pre-adaptations to the local environmental conditions, resulting in a pattern of functional clustering (Cornwell et al. 2006, Ackerly and Cornwell 2007). On the contrary, at the scale of the community the analysis of competitive interactions is more challenging as different functional patterns can be expected depending on the number of resources limiting species fitness (Götzenberger et al. 2012, Gallien et al. 2015). Indeed, it was originally proposed that, when several resources are limiting species coexistence, only the best competitor(s) for exploiting each of these resources would remain once equilibrium is reached, and that less competitive species with intermediate phenotypes should get extinct (due to stabilizing niche differences; MacArthur and Levins 1967, Chesson 2000). Such a mechanism is thus expected to promote functional overdispersion patterns. However, it has been acknowledged and recently investigated at community scales, that if only one resource limits species coexistence (e.g. competition for light in forests; Kunstler et al. 2012), then only the best (or a group of similarly good) competitors for this resource should remain once equilibrium is reached (due to hierarchical fitness differences; 
Gause 1934, Chesson 2000, Mayfield and Levine 2010). Since the best competitors are assumed to share similar traits related to competition for this specific resource (e.g. fast growth and high height at maturity), competition is expected to lead to functional clustering patterns.

To assess the strength of environmental filtering and/ or competition mechanisms, observed functional patterns are usually compared to a random expectation (Gotelli 2000, Wang and Fang 2012). The random expectation is often that species coexistence is not driven by their functional characteristics, and can be derived from randomisations of species functional attributes (i.e. similar to neutral expectations; Hubbell 2001).

Empirical studies applying community ecology approaches have now shown repeated evidence of competitive interactions, most often highlighted by functional overdispersion patterns (Swenson and Enquist 2009, Kraft and Ackerly 2010, Shiono et al. 2015) but also in a few cases by clustering patterns (Kunstler et al. 2012, Kraft et al. 2014, 2015). However, functional trait patterns not different than expected under random assembly are frequently identified (Götzenberger et al. 2012, Spasojevic and Suding 2012), suggesting that competitive interactions may have minor influences on species coexistence.

\section{Are indirect interactions truly negligible?}

Among the various conceptual and methodological reasons that have been proposed to explain the difficulty to detect competitive interactions when analysing community functional diversity patterns (e.g. spatial and taxonomic resolutions: Münkemüller et al. 2014; functional trait selection: Spasojevic and Suding 2012; null model elaboration: Hardy 2008; or species pool definition: Karger et al. 2016), one specific question has received surprisingly limited interest: which functional trait patterns should be expected if competitive interactions are not only direct but also complex and indirect across multiple species?

Indirect competitive interactions arise for instance when the impact of one species on another requires or is modified by the presence of a third species (Wootton 1994). Thus, when interpreting functional diversity patterns in regard to the competition mechanisms described above a fundamental assumption was implicitly made: only direct competition is considered while indirect competition is assumed negligible. In other words, only direct competition is assumed to drive coexistence and to scale up to the community level.

In fact, if all competitive interactions of the system are transitive (symmetric or hierarchical), then omitting indirect interactions does not affect strongly our understanding of coexistence mechanisms since species competitive hierarchy will remain constant. However, if the system contains non-transitive (hereafter called intransitive) interactions, then species competitive hierarchies may become cyclic over time or depend on species relative abundances (Fig. 1; Levine 1976, Huisman and Weissing 1999, 2001). For example, in a hypothetical community with three species $\{A$, $\mathrm{B}, \mathrm{C}\}$, transitive competition would occur when species $\mathrm{A}$ is a better competitor than species $\mathrm{B}$ (denoted here as $\mathrm{A}>\mathrm{B}$ ) and species $C(A>C)$, while species $B$ is better than species $\mathrm{C}(\mathrm{A}>\mathrm{B}>\mathrm{C})$. This would happen for example in a plant community where maximum vegetative height determines competitive ability for light acquisition. On the contrary, intransitive competition would occur if even though $\mathrm{A}>\mathrm{B}$ and $\mathrm{B}>\mathrm{C}$, species $\mathrm{C}$ is a better competitor than species $\mathrm{A}$, which generates an intransitive loop of competitive interactions $\mathrm{A}>\mathrm{B}>\mathrm{C}>\mathrm{A}$ (similar to the 'rock-paper-scissor' game; Gilpin 1975, May and Leonard 1975). This would for instance happen if each species' competitive superiority changes across resources (Fig. 1; Rainey and Travisano 1998, Allesina and Levine 2011).

In such a three species system, the intransitive loop has the emergent property of inducing negative frequency-dependent population growth rates, a stabilizing mechanism that promotes species coexistence (Fig. 1; Durrett and Levin 1998, Huisman and Weissing 1999, Allesina and Levine 2011). This stabilizing effect can be understood intuitively: if the abundance of species $A$ increases, then the abundance of species $B$ will decrease (because $A>B$ ); which will in turn lead to an increase in the abundance of species $\mathrm{C}$ (because $\mathrm{B}>\mathrm{C}$ ), and finally to a decrease in the abundance of species $\mathrm{A}$ (because C > A; Fig. 1). Consequently, by only considering the direct effect of $A$ on $B$ one would conclude that $A$ always wins over $B$, whereas accounting for indirect intransitive interactions would reveals that $\mathrm{A}$ can only outcompete $\mathrm{B}$ if $\mathrm{C}$ is absent.

Interestingly, negative frequency-dependent population growth rates do not always have stabilizing effects on species coexistence. In fact, depending on the intransitive loop length coexistence can be either stabilized (odd-loops) or destabilized (even-loops; Allesina and Levine 2011, Vandermeer 2011). By generalizing the verbal example given previously for a loop with three species it can be easily understood that intransitive loops containing an odd number of species can stabilize species coexistence. If the abundance of species A increases, cascading effects of competition will ultimately lead to a decrease in species A's abundance. On the opposite, loops containing an even number of species have destabilizing effects on species abundances. Indeed, if the abundance of species A increases, then the abundance of species $\mathrm{B}$ decreases, and cascading effects of competition will lead to a further increase in species A's abundance and a further decrease in species $\mathrm{B}$ abundance, which may ultimately drive species B to local extinction (Allesina and Levine 2011, Vandermeer 2011).

\section{Intransitive competition - what we have learnt so far}

Interestingly, although intransitivity has an old history in fields such as sociology, mathematics or economics, intransitive interactions have only been documented since the mid-1970s in ecological studies (Table 1). To clarify what we have learnt so far about intransitive competition, I have reviewed all empirical ecological studies (but not the purely theoretical ones) that investigated intransitive competition since 1975. I specifically focused on two aspects: how does such a mechanism arise in nature, and what is the prevalence of its stabilizing versus destabilizing effects on species coexistence. The literature search was performed on ISI Web of Knowledge in August 2016 with the search terms: ('intransitive competition' OR 'non-transitive competition' OR 'rock-paper-scissors competition' OR 'indirect facilitation' OR 'competitive reversal' [although competitive reversal is not strictly equivalent to intransitivity]) AND 'ecology', then all articles found were screened for relevance as well as for references there in. 


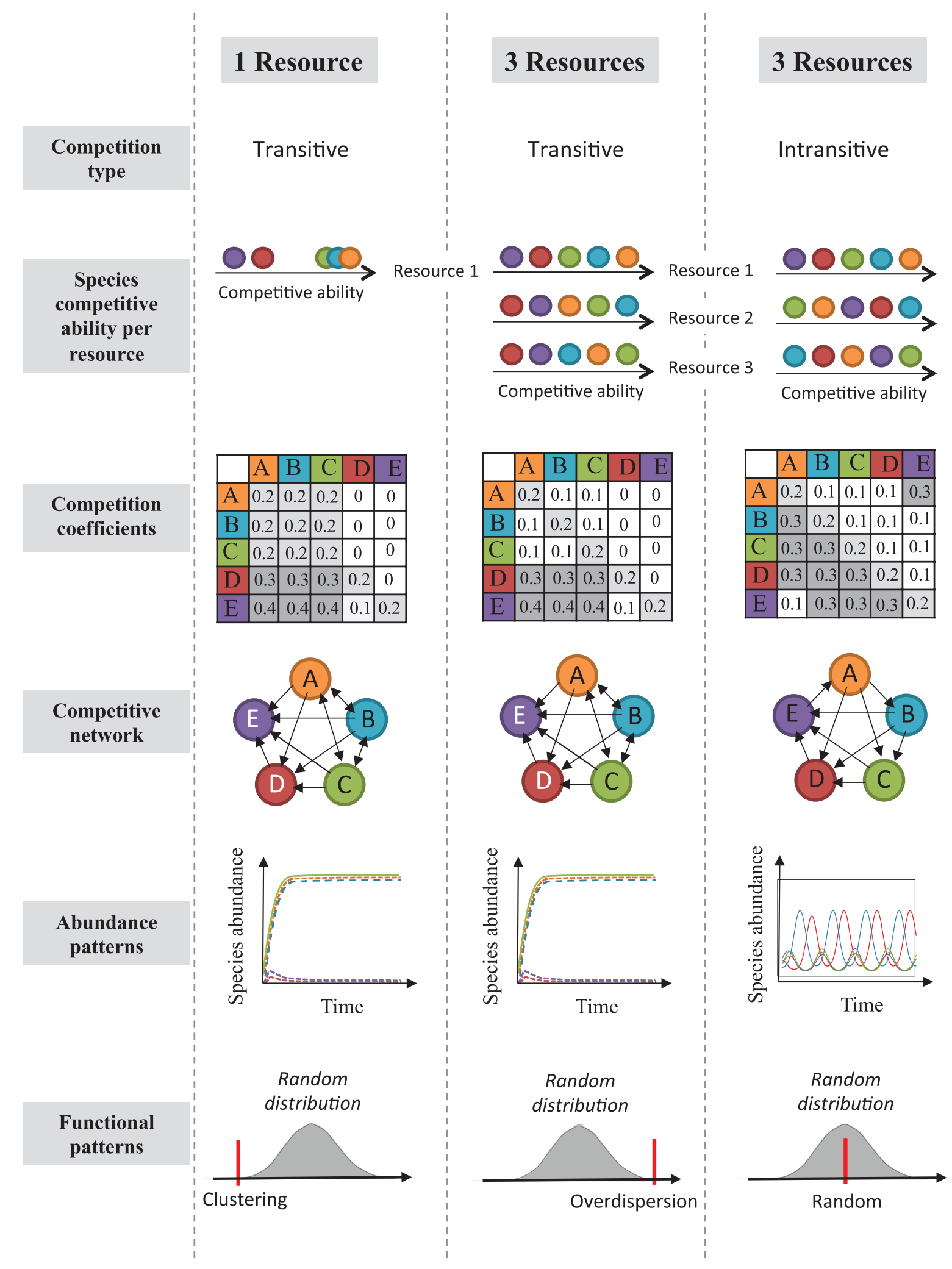

Figure 1. Various representations of the different competition mechanisms. A community of species can coexist on either one (first column) or several resources (second and third columns), and species either interact in transitive (first and second columns) or intransitive (third column) fashions. For each of the available resources, species competitive hierachy is mediated by (at least) one trait (such as plant height for light competition, or root lenght for water uptake). From species competitive hierachies the matrix of pairwise competition coefficients emerges, and can be represented as a competitve network (single-headed arrows point to the weaker competitor, and double-headed arrows indicate symmetric competition). Species highlighted with black letters are the ones stably coexisting in the community, as show in the abundance patterns over time. Finally, functional diversity in the community can be estimated (red vertical line), and compared to a null expectation (for instance calculating community functional diversity while randomizing species traits across the entire species pool). 
Table 1. Empirical and experimental studies aiming at identifying intransitive competition and its mechanisms in nature. The colour shadings highlight studies presenting evidences for intransitive interactions.

\begin{tabular}{|c|c|c|c|c|c|}
\hline Taxon & Intransitive mechanism? & $\begin{array}{l}\text { Evidence of } \\
\text { intransitivity? }\end{array}$ & Main finding & Type & Reference \\
\hline \multirow[t]{11}{*}{ Plants } & \multirow[t]{7}{*}{ No identified mechanism } & no & $\begin{array}{l}\text { Overall competition is weaker than } \\
\text { expected from direct interactions. } \\
\text { Coexistence is not maintained via } \\
\text { intransitivity but indirect facilitation. }\end{array}$ & experimental & $\begin{array}{l}\text { Miller 1994, } \\
\text { Aschehoug and } \\
\text { Callaway } 2015\end{array}$ \\
\hline & & no & No signal of intransitive competition. & experimental & $\begin{array}{l}\text { Law et al. 1997, } \\
\text { Metlen et al. } 2013\end{array}$ \\
\hline & & no & 9/10 case studies show transitivity. & $\begin{array}{l}\text { re-analysis of } \\
\text { experiment }\end{array}$ & Shipley 1993 \\
\hline & & no & $\begin{array}{l}\text { Most cases show transitivity, even with } \\
\text { a relaxed definition of intransitivity } \\
(\mathrm{A}>\mathrm{B}>\mathrm{C} \text { but } \mathrm{A} \text { and } \mathrm{C} \text { coexist). }\end{array}$ & $\begin{array}{l}\text { re-analysis of } \\
\text { experiment }\end{array}$ & $\begin{array}{l}\text { Keddy and Shipley } \\
1989\end{array}$ \\
\hline & & yes & $\begin{array}{l}\text { Intransitivity frequency decreases } \\
\text { during succession. }\end{array}$ & observational & Ulrich et al. 2016 \\
\hline & & yes & $\begin{array}{l}\text { Intransitivity occurs in } 65 \% \text { of sites, } \\
\text { increases with richness and aridity } \\
\text { but decreases with land use intensity. }\end{array}$ & observational & Soliveres et al. 2015 \\
\hline & & yes & $\begin{array}{l}\text { Intransitivity decreases with abiotic } \\
\text { stress. }\end{array}$ & observational & $\begin{array}{l}\text { Bowker and Maestre } \\
2012\end{array}$ \\
\hline & $\begin{array}{l}\text { No identified mechanism, } \\
\text { but suggest combination } \\
\text { of resource depletion and } \\
\text { pre-emption. }\end{array}$ & yes & Suspect intransitive root competition. & experimental & $\begin{array}{l}\text { Armas and Pugnaire } \\
2011\end{array}$ \\
\hline & $\begin{array}{l}\text { No identified mechanism, } \\
\text { but suggest genetic trade- } \\
\text { offs in competitive ability. }\end{array}$ & yes & $\begin{array}{l}\text { First (but weak) signals of intransitive } \\
\text { competition at the genotype level. }\end{array}$ & experimental & $\begin{array}{l}\text { Taylor and Aarssen } \\
1990\end{array}$ \\
\hline & $\begin{array}{l}\text { (2) Species competitive } \\
\text { superiority changes with } \\
\text { life stage. }\end{array}$ & yes & Intransitivity increases with plant age. & experimental & $\begin{array}{l}\text { Zhang and Lamb } \\
2012\end{array}$ \\
\hline & $\begin{array}{l}\text { (5) Toxin production, toxin } \\
\text { resistance and toxin } \\
\text { sensitivity. }\end{array}$ & yes & $\begin{array}{l}\text { Intransitive competition occurs } \\
\text { between two lineages of one species } \\
\text { and the rest of the community. }\end{array}$ & $\begin{array}{r}\text { observational }+ \\
\text { experimental }\end{array}$ & $\begin{array}{l}\text { Lankau and Strauss } \\
\quad 2007\end{array}$ \\
\hline Amoeba & No identified mechanism & no & No signal of intransitive competition. & experimental & Fortunato et al. 2003 \\
\hline \multirow[t]{5}{*}{ Bacteria } & No identified mechanism & no & No signal of intransitive competition. & experimental & $\begin{array}{l}\text { de Visser and Lenski } \\
\text { 2002, Pérez- } \\
\text { Gutiérrez et al. } 2013\end{array}$ \\
\hline & $\begin{array}{l}\text { (1) Species competitiveness } \\
\text { changes across resources. }\end{array}$ & yes & $\begin{array}{l}\text { Intransitive competition allows } \\
\text { coexistence. }\end{array}$ & experimental & $\begin{array}{l}\text { Rainey and Travisano } \\
1998\end{array}$ \\
\hline & $\begin{array}{l}\text { (4) Tradeoff between } \\
\text { resource consumption } \\
\text { and growth rate. }\end{array}$ & yes & $\begin{array}{l}\text { Intransitivity can explain the evolution } \\
\text { and maintenance of altruistic } \\
\text { behaviours. }\end{array}$ & $\begin{array}{l}\text { experimental }+ \\
\text { simulation }\end{array}$ & $\begin{array}{l}\text { Fiegna and Velicer } \\
2005, \text { Nahum et al. } \\
2011\end{array}$ \\
\hline & \multirow[t]{2}{*}{$\begin{array}{l}\text { (5) Toxin production, toxin } \\
\text { resistance and toxin } \\
\text { sensitivity. }\end{array}$} & yes & $\begin{array}{l}\text { First evidence of intransitivity in vivo } \\
\text { (bacteria in mice guts), in a spatially } \\
\text { structured environment. }\end{array}$ & experimental & $\begin{array}{l}\text { Kirkup and Riley } \\
2004\end{array}$ \\
\hline & & yes & $\begin{array}{l}\text { Intransitive competition allows } \\
\text { coexistence. }\end{array}$ & $\begin{array}{l}\text { experimental }+ \\
\text { simulation }\end{array}$ & $\begin{array}{l}\text { Kerr et al. 2002, } \\
\quad \text { Kelsic et al. } 2015\end{array}$ \\
\hline \multirow[t]{6}{*}{$\begin{array}{l}\text { Sessile aquatic } \\
\text { organisms }\end{array}$} & \multirow{2}{*}{$\begin{array}{l}\text { (1) Species competitiveness } \\
\text { changes across resources. } \\
\text { No identified mechanism }\end{array}$} & no & No signal of intransitive competition. & observational & Connell 1978 \\
\hline & & yes & Intransitivity decreases with latitude. & $\begin{array}{l}\text { re-analysis of } \\
\text { experiment }\end{array}$ & Barnes 2002 \\
\hline & $\begin{array}{l}\text { No identified mechanism, } \\
\text { but suggest: }(1) \text { species } \\
\text { competitiveness change } \\
\text { across resources. }\end{array}$ & yes & $\begin{array}{l}\text { Intransitive competition is possible in } \\
\text { nature. }\end{array}$ & experimental & $\begin{array}{l}\text { Buss and Jackson } \\
\text { 1979, Turner and } \\
\text { Todd 1994, Abelson } \\
\text { and Loya } 1999\end{array}$ \\
\hline & \multirow[t]{2}{*}{$\begin{array}{l}\text { (2) Species competitive } \\
\text { superiority changes with } \\
\text { life stage. }\end{array}$} & yes & $\begin{array}{l}\text { Intransitivity can happen when two } \\
\text { species compete for resources and } \\
\text { one for space pre-emption. }\end{array}$ & $\begin{array}{l}\text { observational }+ \\
\text { simulation }\end{array}$ & $\begin{array}{l}\text { Edwards and } \\
\text { Schreiber } 2010\end{array}$ \\
\hline & & yes & Exploitative systems can be intransitive & observational & Buss 1980 \\
\hline & $\begin{array}{l}\text { (5) Toxin production, toxin } \\
\text { resistance and toxin } \\
\text { sensitivity. }\end{array}$ & yes & $\begin{array}{l}\text { Intransitive competition is possible in } \\
\text { nature. }\end{array}$ & observational & $\begin{array}{l}\text { Jackson and Buss } \\
1975\end{array}$ \\
\hline \multirow[t]{2}{*}{ Ants } & No identified mechanism & yes & $\begin{array}{l}\text { Evidence of intransitivity in nest } \\
\text { aggression levels, with a relaxed } \\
\text { definition of intransitivity. }\end{array}$ & observational & Tripet et al. 2006 \\
\hline & $\begin{array}{l}\text { (1) Species competitiveness } \\
\text { changes across resources. }\end{array}$ & yes & $\begin{array}{l}\text { Intransitive competition for nesting } \\
\text { space on Acacia host can emerge } \\
\text { due to host tree variability in sizes. }\end{array}$ & $\begin{array}{r}\text { observational }+ \\
\text { experimental }\end{array}$ & Palmer et al. 2013 \\
\hline izards & $\begin{array}{l}\text { (3) Behavioural tradeoffs for } \\
\text { access to resource. }\end{array}$ & yes & $\begin{array}{l}\text { Three morphs show intransitive fitness } \\
\text { differences with an oscillation of } \\
6 \text {-year period. }\end{array}$ & observational & $\begin{array}{l}\text { Sinervo and Lively } \\
\text { 1996, Zamudio and } \\
\text { Sinervo } 2000\end{array}$ \\
\hline
\end{tabular}




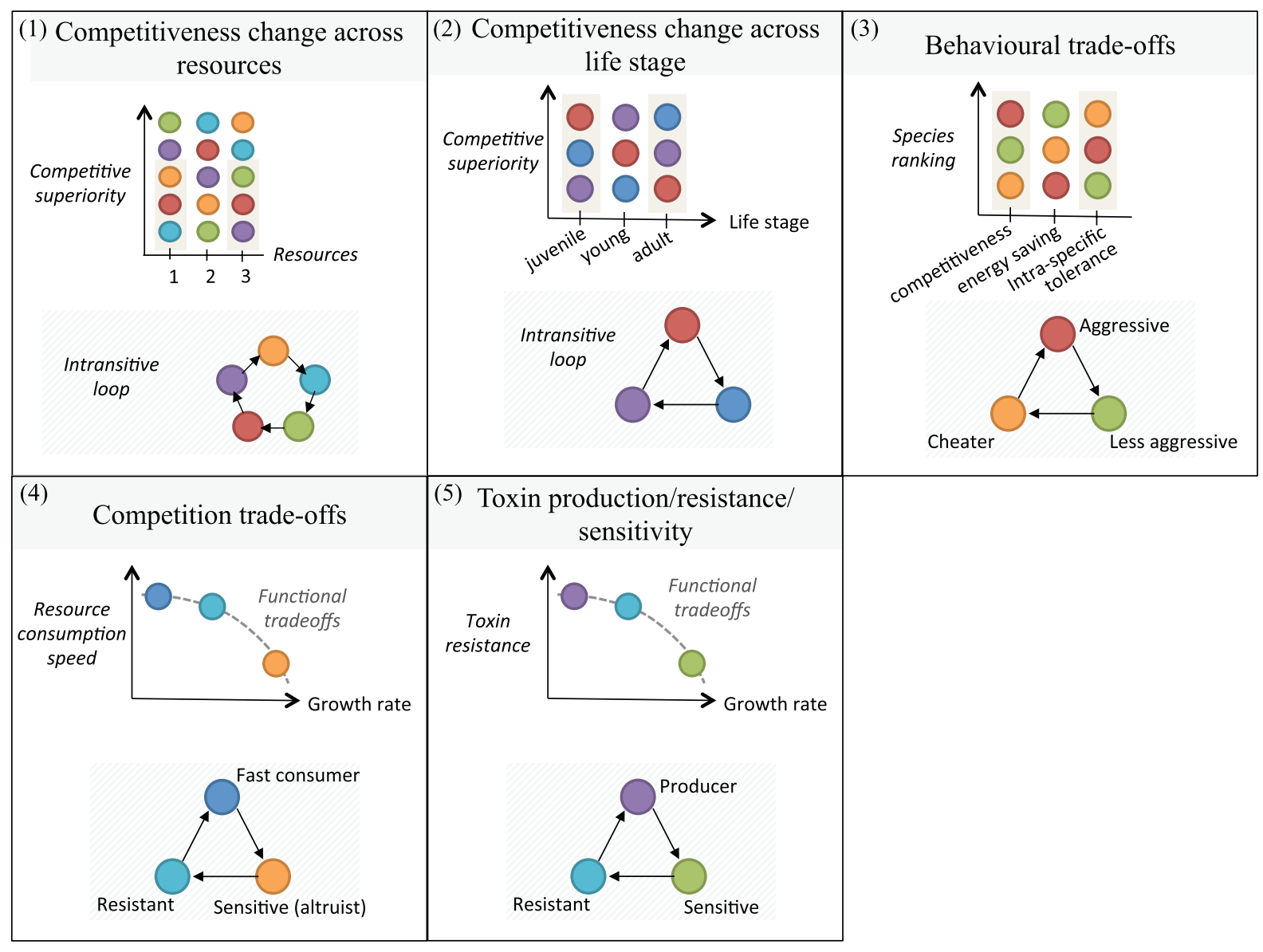

Figure 2. Illustration of the different mechanisms favouring the emergence of intransitive interactions (for literature references see Table 1). Species are indicated with circles of different colours, and competitive superiority indicated by arrows in the competitive network (pointing toward the inferior competitor).

\section{Which mechanisms can lead to intransitivity?}

All mechanisms that have been identified as promoting intransitive competition can be grouped into five categories that are presented below (see the five panels in Fig. 2 for illustrations and Table 1 for examples). For the sake of simplicity, these mechanisms are presented on simplified five- or three-species systems, but can easily be expanded to more diverse systems.

Intransitive competition can emerge from common situations: when species competitive superiority differs across resources (Fig. 2.1), or across species life stages (Fig. 2.2). Indeed, if species competitive abilities vary across resources, then it may result that none of the species can outcompete all others (Palmer et al. 2013). Similarly, if species competitive abilities vary across life stages - with some species being better competitors at juvenile stages compared to other species being more competitive in their mature phase - then none of the species may be able to outcompete the others during all its life stages (Buss 1980, Edwards and Schreiber 2010).

Heritable behavioural tradeoffs for resource acquisition have also been shown to promote intransitive competition in specific situations (Fig. 2.3). For instance, three behavioural strategies like very aggressive, less aggressive and cheater, that are heritable and mediated by a series of competition cost and benefices (ranking differently across species), will create the necessary conditions for specific behaviours to be favoured when rare. Aggressive behaviour becomes a cost when too abundant, and thus a population of individuals with aggressive behaviour can be invaded by cheaters, but when cheaters are too abundant the population can in turn be invaded by individuals with less aggressive behaviours, which can in turn be invaded by aggressive individuals when too abundant (Sinervo and Lively 1996).

Similarly, tradeoffs between species growth rates and resource consumption speed (Fig. 2.4), or toxin production have been shown to lead to intransitivity in various natural systems (Fig. 2.5; Table 1). Tradeoffs between species growth rates and resource consumption speed can generate intransitive loops where a rare fast consumer has a competitive advantage compared to a slow consumer, which in turn has a growth advantage compared to an intermediate but stress resistant consumer, which itself has a growth advantage compared to the fast consuming species (Nahum et al. 2011). This type of intransitive loop has notably been identified as enabling the evolution and maintenance of altruistic behaviours (Nahum et al. 2011). Several empirical cases studies have also documented evidence of intransitive coexistence of three species (or lineages): producing toxic compounds (C), resisting to the toxin $(\mathrm{R})$, and being sensitive to the toxin $(\mathrm{S})$. In this case species show differences in their sensitivity to the toxin $(C=R>S)$, but they also show differences in their growth rates $(S>R>C)$. Therefore sensitive species have 
a growth advantage compared to resistant species, which in turns have a growth advantage above toxic species, which can kill the sensitive species (Jackson and Buss 1975, Kerr et al. 2002, Kirkup and Riley 2004, Lankau and Strauss 2007).

The five described general mechanisms that can lead to the emergence of intransitive competition (Fig. 2) are relatively simple and thus likely to be frequent in natural systems, especially in species rich systems where species interactions are complex (e.g. phytoplankton, plant or insect assemblages; Huisman and Weissing 1999, Huisman et al. 2001, Allesina and Levine 2011). Additionally, this list of mechanisms is certainly not exhaustive, and more empirical work will surely reveal additional intransitive mechanisms. Therefore, although only 24 case studies reported evidences for intransitive competition (Table 1), its actual frequency in nature is likely underestimated.

The review also highlights the need for additional studies investigating the presence or absence of intransitive interactions, and specifically for studies on a larger range of biological systems (including birds, fishes, and mammals). Indeed, up to now only a narrow set of organisms has been investigated in this context: plants $(n=13)$, microorganisms $(n=9)$, sessile aquatic organisms $(n=8)$, ants $(n=2)$ and lizards $(n=2)$. Repeated analyses across a variety of taxa will allow identifying which type of species assemblages is most prone to which type of intransitive mechanism. For instance, when considering the set of intransitive studies to date it seems that tradeoffs between species growth rates and toxin production (Fig. 2.5) have been more documented than all other types of intransitive mechanisms (i.e. in plants, bacteria and aquatic systems; Jackson and Buss 1975, Kerr et al. 2002, Kirkup and Riley 2004, Lankau and Strauss 2007), but whether it reflects its 'true' prevalence in nature or just a bias in the types of experiments performed so far remains to be elucidated.

\section{Empirical evidence for stabilizing effects?}

Overall, only 34 empirical studies have investigated presence or absence of intransitive competitive interactions in natural or experimental systems (Table 1). Among them, 24 studies $(71 \%)$ found evidences of intransitive competition between species or lineages (Kirkup and Riley 2004, Lankau and Strauss 2007). Interestingly, all these 24 studies revealed or suggested positive stabilizing effects of intransitivity, while none to date has documented a potential destabilizing effect in natural systems.

Studying the destabilizing effects of intransitive interactions is actually difficult, as they push the system away from equilibrium (Allesina and Levine 2011). Indeed, when an intransitive loop of an even number of species emerges, some species will be favoured by the loop and thus increase in abundances, while the others will be disfavoured and decrease in abundances over time until ultimately one of them gets extinct. After the first species extinction, the system may however stabilize again since a new odd intransitive loop might have emerged (Allesina and Levine 2011, Vandermeer 2013). Consequently, studying destabilizing effects of intransitivity may require the long-term study of a system that is not at equilibrium or the experimental perturbation of stabilizing (odd-length) intransitive loops. For instance, once a stabilizing loop has been found in nature (or assembled experimentally) it is then possible to physically remove one of the species participating to this loop so that an even-length destabilizing loop emerges and can be studied over time. Although destabilizing intransitive effects are often described as leading to the extinction of at least one species (Allesina and Levine 2011, Vandermeer 2013), it is nonetheless possible that if species possess stabilizing niche differences (and can therefore coexist without intransitivity) even-length intransitive loops will only lead to a decrease in half of the species abundances (the ones that are disadvantaged by the loop).

\section{Intransitive competition leads to random trait diversity patterns}

This short review of empirical evidence of intransitive competition mechanisms suggests that such mechanisms might be rather common in nature. However, the consequences of intransitive interactions on community functional diversity patterns have never been investigated so far.

To explore the functional community patterns that can be generated by intransitive interactions I built a theoretical model. The simulations were performed in three steps: 1) a pool of species that have different rankings on three functional traits in a way that intransitive competition network emerges was first created, then 2) I simulated the community assembly from this species pool, and 3) once the community had reached quasi-equilibrium, signals of community functional clustering or overdispersion were estimated (see the Supplementary material Appendix 1 for more details about the simulation model). To apply this approach I first generated different species pools of various sizes (10 000 species pools of 10, 20, 50 and 100 species). I then used the competition network model published by Allesina and Levine (2011) to simulate community assembly dynamics. From these simulated communities I estimated community functional diversity patterns with one the most commonly used diversity measure: the standardized effect size of the mean functional distance of the community: $\mathrm{MFD}_{\mathrm{SES}}$, weighted or not by species abundances (Webb et al. 2002; see Box 1 and Supplementary material Appendix 1 for more details on the simulations).

These simple simulations (which thus made very few assumptions on species coexistence) demonstrate that when species coexistence is promoted by intransitive competition then random functional community patterns emerge (Fig. 3c, Box 1). In other words, on average, species coexisting via intransitive competition do not show significant signals of functional clustering or overdispersion (as usually expected from competitive interactions; Mayfield and Levine 2010). Indeed, under intransitive competition what is important for species coexistence is not their specific functional traits but rather their various rankings along several trait gradients, which thus does not guarantee any functional clustering or overdispersion signals. It can be noted that this result does not seem to be affected by the size of the species pool, or the use of species relative abundances when calculating the MFD index. Overall, these results contradict traditional expectations that competitive interactions can be captured by the analysis of community functional structure, at least with the available methodological tools. 


\section{Box 1}

\section{Functional trait patterns under intransitive competition}

Model. To simulate the community assembly I used the competition tournament model of Allesina and Levine (2011). The model was specified so that species were competing for three limiting resources. For each resource, species hierarchy was set up by their position on a trait gradient (drawn at random from a normal distribution). Species ranking on these three traits was then used to build the payoff matrix and thus to determine the competition networks. More details on the model can be found in Supplementary material Appendix 1.

Simulations. 100000 species pools of different sizes were generated ( $\mathrm{n}=10,20,50$ and 100 species). The competition networks obtained from each of these species pools were then used to simulate species coexistence (see example in Fig. $3 \mathrm{a}$ ) and identify the species pools leading to the coexistence of multiple species via intransitive competition (intransitive communities). Ten thousand intransitive communities (of three to nine species) per species pool size were kept for the analysis of functional diversity patterns. Community functional diversity (MFD) was estimated as the mean functional distance between the co-occurring species (using pairwise Euclidian trait differences). MFD's deviation from null expectations: $\mathrm{MFD}_{\mathrm{SES}}$, was determined by 99 randomizations of the functional trait attributes across the species of the species pool. $\mathrm{MFD}_{\mathrm{SES}}$ varies between 0 (perfectly similar species) and 1 (completely dissimilar species), and $\mathrm{MFD}_{\mathrm{SES}}<0.025$ indicates that species are significantly more similar than expected by chance, whereas $\mathrm{MFD}_{\mathrm{SES}}>0.975$ indicates that species are significantly less similar than expected by chance. $M_{\text {FES }}$ can be tracked over time (example in Fig. 3b), and averaged over a stable time period once species abundances have reached quasi-equilibrium (Fig. 3c). More details on the simulations can be found in the Supplementary material Appendix 1.

Results. Under intransitive competition the functional diversity of simulated community shows on average random functional patterns of $\mathrm{MFD}_{\mathrm{SES}}$ (i.e. $0.05<$ mean $\mathrm{MFD}_{\mathrm{SES}}<0.975$ ). This is true for all species pool sizes (Fig. 3c).

\section{Consequences for community ecology and ways forwards}

Considering all mechanisms that can generate intransitive competition in natural systems (Fig. 2), it seems reasonable to hypothesise that intransitive competition is frequent in nature (Sinervo and Lively 1996, Kirkup and Riley 2004). However, methods to infer community assembly processes from traits pattern in community ecology are unable to detect such complex indirect interactions (Box 1, Fig. 3c). Thus, the importance of competition as a structuring force, limiting but also promoting species coexistence, is currently underestimated.

Based on the literature review and community assembly simulations presented above, three main conclusions can be (a)

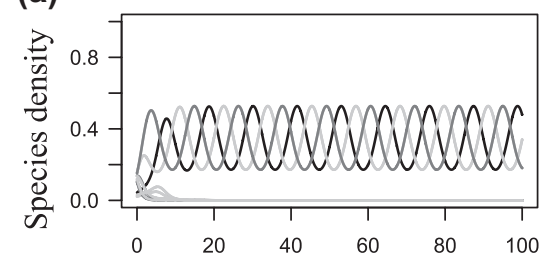

(b)

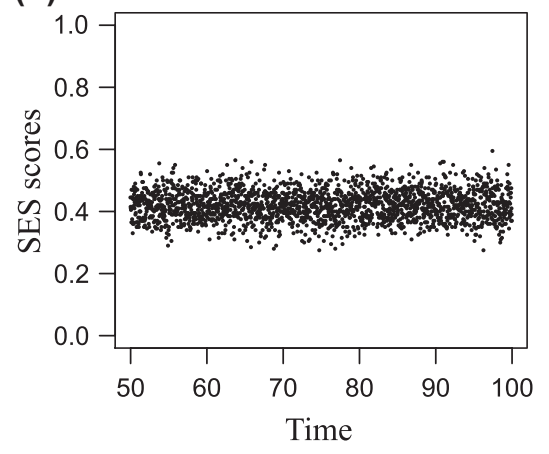

(c)

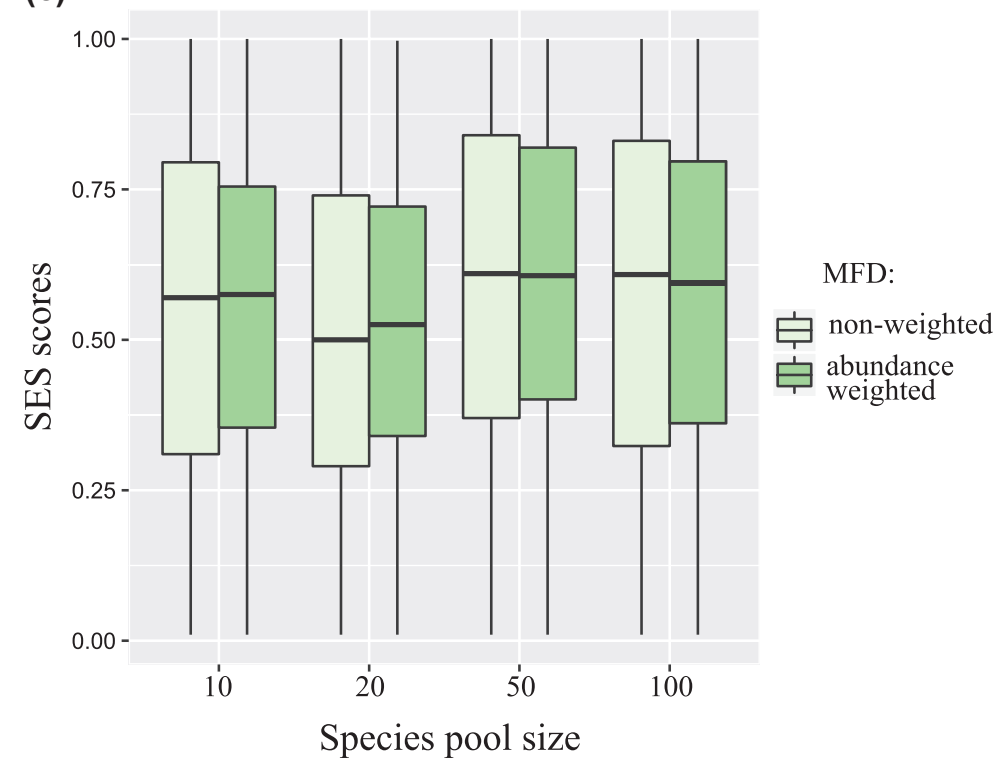

Figure 3. Once species coexistence, via intransitive competition, is generated (see an example in (a)), then the MFD $\mathrm{SES} \mathrm{scores}_{\mathrm{San}}$ be estimated at each time step (see an example in (b)). Finally, (c) the sensitivity of MFD $_{\text {SES }}$ scores to the species pool size (10-20-50-100 species) and to species relative abundances (light versus dark green colours of the boxplots) was estimated (10 000 intransitive communities per species pools size). In boxplots the middle black lines represent the median, boxes show the 25 th and 75 th percentiles, and whiskers show the 10th and 90th percentiles. 
drawn. First, simulations highlight that more caution is needed when interpreting random functional community patterns, especially in situations favouring the emergence of intransitive competition (such as species rich systems where species coexistence is known to be limited by several resources or where competitive tradeoffs are expected). Indeed, classical null models (e.g. randomizing species functional traits) are unable to detect signals of intransitive competitive interactions.

Second, this complex indirect competition mechanism has been understood from empirical evidence, but yet not formally integrated into modern coexistence theory, where most emphasis is given to the relative importance of stabilizing niche differences and transitive fitness differences (Chesson 2000). Integrating intransitive competition into coexistence theory would enable the formal evaluation of its properties in simple (e.g. 3-species intransitive loop, as in Fig. 2) but also more complex systems (e.g. where multiple intransitive loops of different lengths can interplay, or when different types of competition interact).

Third, there are urgent needs for the development of new methods able to detect complex indirect interactions in natural and experimental systems. Among the promising avenues to fulfil this need is the empirical calibration of matrices of competition coefficients at the community level. Matrices of competition coefficients are matrices of intra- and inter-specific competition coefficients that could be estimated for all pairs of species in a community, and which could be used to identify the presence of indirect competitive interactions (e.g. by deriving the competition network from the pairwise competition coefficients). Doing so is not impossible as it has been already done for simple systems, either using competition experiments (Levine and HilleRisLambers 2009, Gremer et al. 2013, Narwani et al. 2013) or phenomenological population dynamic models parameterized with field-based vital rates and interaction coefficients (Adler et al. 2010, Chu and Adler 2015). Ultimately, if species pairwise competition coefficients can be clearly linked to species trait differences (Kraft et al. 2015), it may finally be possible to design specific functional dissimilarity measures (or null model randomizations) that will enable the detection of intransitive interactions from community functional trait structure.

Overall, expanding our focus from direct to complex indirect interactions, or competitive networks, will permit to shift our current understanding of coexistence mechanisms toward a more dynamic vision of species assemblages.

Acknowledgements - I am very thankful to Florian C. Boucher, Tamara Münkemüller, Wilfried Thuiller and Damaris Zurell for their review of the manuscript and constructive comments.

\section{References}

Abelson, A. and Loya, Y. 1999. Interspecific aggression among stony corals in Eilat red sea: a hierarchy of aggression ability and related parameters. - Bull. Mar. Sci. 65: 851-860.

Ackerly, D. D. and Cornwell, W. K. 2007. A trait-based approach to community assembly: partitioning of species trait values into within- and among-community components. - Ecol. Lett. 10: 135-145.
Adler, P. B. et al. 2010. Coexistence of perennial plants: an embarrassment of niches. - Ecol. Lett. 13: 1019-1029.

Allesina, S. and Levine, J. M. 2011. A competitive network theory of species diversity. - Proc. Natl Acad. Sci. USA 108: 5638-5642.

Armas, C. and Pugnaire, F. I. 2011. Plant neighbour identity matters to belowground interactions under controlled conditions. - PLoS ONE 6: e27791.

Aschehoug, E. T. and Callaway, R. M. 2015. Diversity increases indirect interactions, attenuates the intensity of competition and promotes coexistence. - Am. Nat. 186: 452-459.

Barnes, D. K. A. 2002. Polarization of competition increases with latitude. - Proc. R. Soc. B 269: 2061-2069.

Bowker, M. A. and Maestre, F. T. 2012. Inferring local competition intensity from patch size distributions: a test using biological soil crusts. - Oikos 121: 1914-1922.

Buss, L. W. 1980. Competitive intransitivity and size-frequency distributions of interacting populations. - Proc. Natl Acad. Sci. USA 77: 5355-5359.

Buss, L. W. and Jackson, J. B. C. 1979. Competitive networks: nontransitive competitive relationships in cryptic coral reef environments. - Am. Nat. 113: 223-234.

Chesson, P. 2000. Mechanisms of maintenance of species diversity. - Annu. Rev. Ecol. Syst. 31: 343-366.

Chu, C. and Adler, P. B. 2015. Large niche differences emerge at the recruitment stage to stabilize grassland coexistence. - Ecol. Monogr. 85: 373-392.

Connell, J. H. 1978. Diversity in tropical rain forests and coral reefs. - Science 199: 1302-1310.

Cornwell, W. K. et al. 2006. A trait-based test for habitat filtering: convex hull volume. - Ecology 87: 1465-1471.

de Visser, J. A. G. and Lenski, R. E. 2002. Long-term experimental evolution in Escherichia coli. XI. Rejection of non-transitive interactions as cause of declining rate of adaptation. - BMC Evol. Biol. 8: 2-19.

Durrett, R. and Levin, S. 1998. Spatial aspects of interspecific competition. - Theor. Popul. Biol. 53: 30-43.

Edwards, K. F. and Schreiber, S. J. 2010. Preemption of space can lead to intransitive coexistence of competitors. - Oikos 119: 1201-1209.

Fiegna, F. and Velicer, G. J. 2005. Exploitative and hierarchical antagonism in a cooperative bacterium. - PLoS Biol. 3: 1980-1987.

Fortunato, A. et al. 2003. A linear dominance hierarchy among clones in chimeras of the social amoeba Dictyostelium discoideum. - J. Evol. Biol. 16: 438-445.

Gallien, L. et al. 2015. Contrasting the effects of environment, dispersal and biotic interactions to explain the distribution of invasive plants in alpine communities. - Biol. Invas. 17: 1407-1423.

Gause, G. F. 1934. The struggle for existence. - The Williams \& Wilkins Co.

Gilpin, M. E. 1975. Limit cycles in competition communities. - Am. Nat. 109: 51-60.

Gotelli, N. 2000. Null model analysis of species co-occurrence patterns. - Ecology 81: 2606-2621.

Götzenberger, L. et al. 2012. Ecological assembly rules in plant communities-approaches, patterns and prospects. - Biol. Rev. 87: $111-127$.

Gremer, J. R. et al. 2013. Wate-use efficiency and relative growth rate mediate competitive interactions in Sonoran Desert winter annual plants. - Am. J. Bot. 100: 2009-2015.

Hardy, O. J. 2008. Testing the spatial phylogenetic structure of local communities: statistical performances of different null models and test statistics on a locally neutral community. - J. Ecol. 96: 914-926.

Hubbell, S. P. 2001. The unified neutral theory of species abundance and diversity. - Princeton Univ. Press.

Huisman, J. and Weissing, F. J. 1999. Biodiversity of plankton by species oscillations and chaos. - Nature 402: 407-410. 
Huisman, J. and Weissing, F. J. 2001. Biological conditions for oscillations and chaos generated by multispecies competition. - Ecology 82: 2682-2695.

Huisman, J. et al. 2001. Towards a solution of the plankton paradox: the importance of physiology and life history. - Ecol. Lett. 4: 408-411.

Jackson, J. B. and Buss, L. 1975. Alleopathy and spatial competition among coral reef invertebrates. - Proc. Natl Acad. Sci. USA 72: $5160-5163$.

Karger, D. N. et al. 2016. Delineating probabilistic species pools in ecology and biogeography. - Global Ecol. Biogeogr. 25: 489-501.

Keddy, P. A. and Shipley, B. 1989. Competitive hierarchies in herbaceous plant communities. - Oikos 54: 234-241.

Kelsic, E. D. et al. 2015. Counteraction of antibiotic production and degradation stabilizes microbial communities. - Nature 521: 516-519.

Kerr, B. et al. 2002. Local dispersal promotes biodiversity in a reallife game of rock-paper-scissors. - Nature 418: 171-174.

Kirkup, B. C. and Riley, M. A. 2004. Antibiotic-mediated antagonism leads to a bacterial game of rock-paper-scissors in vivo. - Nature 428: 412-414.

Kraft, N. J. B. and Ackerly, D. D. 2010. Functional trait and phyloge netic tests of community assembly across spatial scales in an Amazonian forest. - Ecol. Monogr. 80: 401-422.

Kraft, N. J. B. et al. 2014. Functional trait differences and the outcome of community assembly: an experimental test with vernal pool annual plants. - Oikos 123: 1391-1399.

Kraft, N. J. B. et al. 2015. Plant functional traits and the multidimensional nature of species coexistence. - Proc. Natl Acad. Sci. USA 112: 797-802.

Kunstler, G. et al. 2012. Competitive interactions between forest trees are driven by species' trait hierarchy, not phylogenetic or functional similarity: implications for forest community assembly. - Ecol. Lett. 15: 831-840.

Lankau, R. A. and Strauss, S. Y. 2007. Mutual feedbacks maintain both genetic and species diversity in a plant community. - Science 317: 1561-1563.

Law, R. et al. 1997. Non-manipulative estimates of competition coefficients in a montane grassland community. - J. Ecol. 85: 505-517.

Levine, S. H. 1976. Competitive interactions in ecosystems. - Am. Nat. 110: 903-910.

Levine, J. M. and HilleRisLambers, J. 2009. The importance of niches for the maintenance of species diversity. - Nature 461: 254-257.

MacArthur, R. H. and Levins, R. 1967. The limiting similarity, convergence and divergence of coexisting species. - Am. Nat. 101: 377-385.

May, R. M. and Leonard, W. J. 1975. Nonlinear aspects of competition between three species. - SIAM J. Appl. Math. 29: 243-253.

Mayfield, M. M. and Levine, J. M. 2010. Opposing effects of competitive exclusion on the phylogenetic structure of communities. - Ecol. Lett. 13: 1085-1093.

Metlen, K. L. et al. 2013. Competitive outcomes between two exotic invaders are modified by direct and indirect effects of a native conifer. - Oikos 122: 632-640.

Miller, T. E. 1994. Direct and indirect species interactions in an early old-field plant community. - Am. Nat. 143: 1007-1025.

Münkemüller, T. et al. 2014. Scale decisions can reverse conclusions on community assembly processes. - Global Ecol. Biogeogr. 23: 620-632.

Nahum, J. R. et al. 2011. Evolution of restraint in a structured rock-paper-scissors community. - Proc. Natl Acad. Sci. USA 108: 10831-10838.

Supplementary material (available online as Appendix oik04033 at <www.oikosjournal.org/appendix/oik-04033>). Appendix 1.
Narwani, A. et al. 2013. Experimental evidence that evolutionary relatedness does not affect the ecological mechanisms of coexistence in freshwater green algae. - Ecol. Lett. 16: 1373-1381.

Palmer, T. M. et al. 2013. A role for indirect facilitation in maintaining diversity in a guild of African acacia ants. - Ecology 94: 1531-1539.

Pérez-Gutiérrez, R.-A. et al. 2013. Antagonism influences assembly of a Bacillus guild in a local community and is depicted as a food-chain network. - ISME J. 7: 487-497.

Rainey, P. B. and Travisano, M. 1998. Adaptive radiation in a heterogeneous environment. - Nature 394: 69-72.

Shiono, T. et al. 2015. Climatic drivers of trait assembly in woody plants in Japan. - J. Biogeogr. 42: 1176-1186.

Shipley, B. 1993. A null model for competitive hierarchies in competition matrices. - Ecology 74: 1693-1699.

Sinervo, B. and Lively, C. M. 1996. The rock-paper-scissors game and the evolution of altermative male strategies. - Nature 380: 240-243.

Soliveres, S. et al. 2015. Intransitive competition is widespread in plant communities and maintains their species richness. - Ecol. Lett. 18: 790-798.

Spasojevic, M. J. and Suding, K. N. 2012. Inferring community assembly mechanisms from functional diversity patterns: the importance of multiple assembly processes. - J. Ecol. 100: 652-661.

Swenson, N. G. and Enquist, B. J. 2009. Opposing assembly mechanisms in a Neotropical dry forest: implications for phylogenetic and functional community ecology. - Ecology 90: 2161-2170.

Taylor, D. R. and Aarssen, L. W. 1990. Complex competitive relationships among genotypes of three perennial grasses: implications for species coexistence. - Am. Nat. 136: 305-327.

Tripet, F. et al. 2006. Kin recognition and the paradoxical patterns of aggression between colonies of a Mojave desert Pheidole ant. - Insectes Soc. 53: 127-135.

Turner, S. J. and Todd, C. D. 1994. Competition for space in encrusting bryozoan assemblages: the influence of encounter angle, site and year. - J. Mar. Biol. Ass. UK 74: 603-622.

Ulrich, W. et al. 2016. Species interactions and random dispersal rather than habitat filtering drive community assembly during early plant succession. - Oikos 125: 698-707.

Vandermeer, J. 2011. Intransitive loops in ecosystem models: from stable foci to heteroclinic cycles. - Ecol. Complex. 8: 92-97.

Vandermeer, J. 2013. Forcing by rare species and intransitive loops creates distinct bouts of extinction events conditioned by spatial pattern in competition communities. - Theor. Ecol. 6: 395-404.

Wang, X. and Fang, J. 2012. Constraining null models with environmental gradients: a new method for evaluating the effects of environmental factors and geometric constraints on geographic diversity patterns. - Ecography 35: 1147-1159.

Webb, C. O. et al. 2002. Phylogenies and community ecology. - Annu. Rev. Ecol. Syst. 33: 475-505.

Weiher, E. and Keddy, P. 1999. Ecological assembly rules: perspectives, advances, retreats. - Cambridge Univ. Press.

Wootton, J. T. 1994. The nature and consequences of indirect effects in ecological communities. - Annu. Rev. Ecol. Syst. 25: 443-466.

Zamudio, K. R. and Sinervo, B. R. 2000. Fertilization as alternative male mating strategies. - Proc. Natl Acad. Sci. USA 97: 14427-14432.

Zhang, S. and Lamb, E. G. 2012. Plant competitive ability and the transitivity of competitive hierarchies change with plant age. - Plant Ecol. 213: 15-23. 